\title{
RESPONSES OF THE VEINS AND ARTERIOLES OF THE FORE- ARM TO WALKING DURING ACCLIMATIZATION TO HEAT IN MAN *
}

\author{
By J. EDWIN WOOD $†$ AND DAVID E. BASS $\ddagger$ \\ (From the Physiology Branch, Quartermaster Research and Engineering Center, Natick, Mass.; \\ the Evans Memorial and Massachusetts Memorial Hospitals; and the Department \\ of Medicine, Boston University School of Medicine, Boston, Mass.)
}

(Submitted for publication August 18, 1959; accepted February 4, 1960)

When a man attempts to exercise for the first time in a hot environment he may experience palpitation, weakness, headache, nausea, vomiting, dizziness or even syncope. These difficulties often prevent him from completing work that could be performed easily in a cool environment. This relatively benign syndrome, heat exhaustion, has been ascribed in part to the inability of the heart to maintain an adequate flow of blood simultaneously through the dilated blood vessels of the periphery and the exercising muscles and to the central nervous system (1). If the man attempts to repeat the task in the heat several times daily, a marked improvement in performance occurs within four days, that is, he no longer experiences heat exhaustion and he can complete the work with relative ease (2). It has been shown that the pulse rate during a given task becomes progressively slower as this acclimatization to heat occurs $(2,3)$. The elevated rectal temperature induced by a standard exercise in the heat decreases in a similar pattern (4). These observations suggest that during the first few days of such experiments the cardiovascular system responds to work in a progressively more effective manner. This improved response could result from an increased cardiac output or from a redistribution of the cardiac output. An increased stroke output might be facilitated by an increased pressure in the right atrium; this, in turn, could

\footnotetext{
* This study was supported by a grant from the Life Insurance Medical Research Fund. Presented in part at the Annual Meeting of the American Physiological Society, April 15, 1959.

† Formerly, Special Research Fellow of the National Heart Institute. Present address: Department of Medicine, Medical College of Georgia, Augusta, Ga.

$\$$ Present address: Physiology Branch, Environmental Protection Division, Quartermaster Research and Engineering Center, U. S. Army, Natick, Mass.
}

be due either to constriction of the peripheral veins (5-7) or to an increased blood volume. It has been found, however, that an increase in blood volume need not accompany acclimatization to heat in man (8). Regarding cardiac output, an altered distribution might result from a reduction of the flow of blood in the skin and skeletal muscles. The purpose of the present study was to investigate responses of the veins and arterioles of the forearm with respect to their roles in the process of acclimatization of man to heat.

\section{METHODS}

Seven volunteer soldiers were acclimatized by repeated exercise in a heated chamber. The age of the subjects ranged from 20 to 23 years. The medical histories, physical examinations and laboratory tests which included hemoglobin determinations, urinalyses and X-ray examinations of the chest indicated that the men were normal. They had been stationed in Massachusetts for at least one year. The men had been subjects for experiments which were similar to those of the present investigation; however, they had not been exposed to a hot environment for at least 3 months prior to the present study, with the exception of Subject 1 who participated in both groups of experiments described below. The subjects were accustomed to work of the type required for these experiments.

Two separate studies were performed. Four of the soldiers served as subjects for the first study and four were used in the second study. Subject 1 participated on both occasions. The first study took place during August 4th through August 15th. In this study the men (Subjects 1, 2, 3, 4) were acclimatized to heat for 9 consecutive days. The second study was conducted from October 7 th through October 13th. This study (Subjects $5,6,7,1$ ) was similar in every respect to the first except that the period of acclimatization to heat was 6 days. Control measurements were made for 2 and 1 days, respectively, before the two studies. The control conditions (the control environment) were: $77^{\circ} \pm 1^{\circ} \mathrm{F}$, relative humidity 40 to 50 per cent. Heat exposures were begun on the day following the respective control periods. The conditions in the heat 


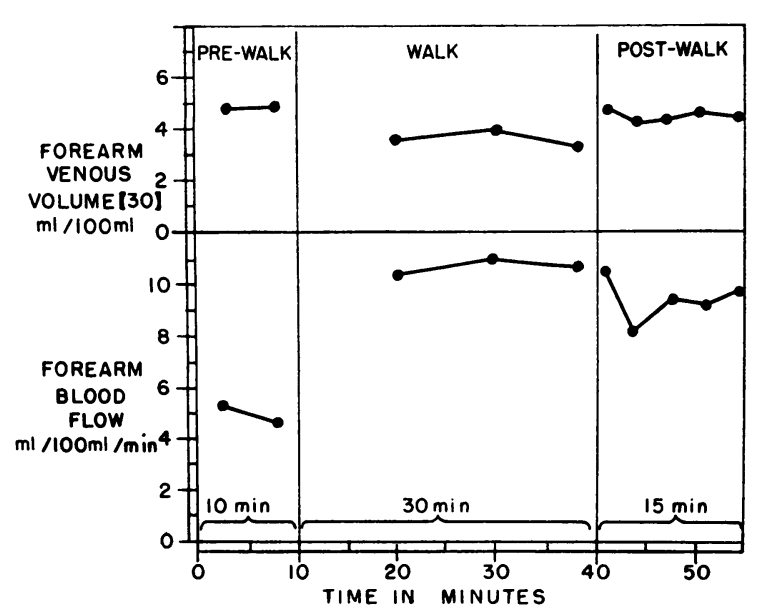

Fig. 1. Individual values of Forearm venous volUME [30] AND FOREARM BLOOD FLOW OBTAINED ON SUbJECT 6 ON DAy 4 In the hot environment. The times when these values were obtained before (pre-walk), during (walk), and after (post-walk) walking on the treadmill for this subject, as well as for the other subjects, are shown.

(the hot environment) were: $120^{\circ} \pm 1^{\circ} \mathrm{F}$ dry bulb, $80^{\circ}$ $\pm 2^{\circ} \mathrm{F}$ wet bulb. The standard exercise consisted in walking for 30 minutes at 3.5 miles per hour on a treadmill with a 5 per cent grade. Each subject performed this task 4 times daily, twice in the morning and twice in the afternoon. The subjects wore army "fatigue" uniforms in the control environment so that they would not feel cool immediately after walking. In the hot environment they wore only shorts. The soldiers lived at prevailing climatic temperatures when they were not walking in the constant temperature chamber. They were required to be in bed by 11 p.m. each night. They were not allowed to drink alcoholic beverages.

The pressure-volume curves of the veins in the forearm and the rates of the flow of blood in the forearm of each subject were obtained just before (2 determinations within 10 minutes), during ( 3 determinations after 10,20 , and 30 minutes of walking, respectively) and immediately after ( 5 determinations in 15 minutes) one of the 4 walks on each day (Figure 1). Measurements of rectal temperature (by thermocouple), pulse rate (by palpation) and arterial blood pressure (by auscultation) were obtained before starting and just prior to the conclusion of this walk. The subjects were studied in the same sequence and at the same time each day. The subject rested on a cot outside the constant temperature chamber for a period of 45 minutes at an ambient temperature of 70 to $75^{\circ} \mathrm{F}$ just prior to the walk in which these measurements were to be made. The subject then stood on the treadmill for 10 to 15 minutes while his arm was being placed in a plethysmograph. He was encouraged to move his legs intermittently during periods of standing unless plethysmographic tracings were being obtained. Water was permitted ad lib.
The pressure-volume curves of the veins of the forearm were obtained with a previously described plethysmographic method (6). This method allows measurement of the change in volume of the veins of the forearm which accompanies a change of transmural pressure of these veins of 1 to $31 \mathrm{~mm} \mathrm{Hg}$. This change of volume of the veins in milliliters per $100 \mathrm{ml}$ of forearm tissue that resulted from a change of effective venous pressure of $30 \mathrm{~mm} \mathrm{Hg}$ is referred to hereafter as venous volume [30]. The initial linear rate of change of the venous pressure-volume tracing could be recalculated in terms of milliliters per $100 \mathrm{ml}$ of forearm tissue per minute and is referred to hereafter as blood flow.

In these experiments the distal chamber of the twochambered plethysmograph was 16.6 rather than $8.5 \mathrm{~cm}$ long as originally described (6). Changes of the volume of the forearm were recorded from a calibrated Brody bellows. When the subject was walking and a plethysmographic record was being obtained, the bellows system was damped to the extent that was necessary to prevent recording of artifacts produced by random movements of the forearm. This was accomplished by adjusting a clamp placed on the hose leading to the bellows.

Arterial occlusion was applied to the wrist prior to each measurement. The temperature of the water in the plethysmograph was kept at $92^{\circ} \mathrm{F}$ in all experiments. The volume of the segment of the forearm enclosed in the distal chamber of the plethysmograph was determined by displacement of water. This was measured as soon as the subject removed his arm from the plethysmograph.

Venous pressure was measured in the control environment and in the hot environment in the first of the two studies in all four subjects. Venous pressure was measured from an antecubital vein with the arm dependent before, during, and after a walking period in which plethysmographic measurements were not performed. The pressure within the vein was measured

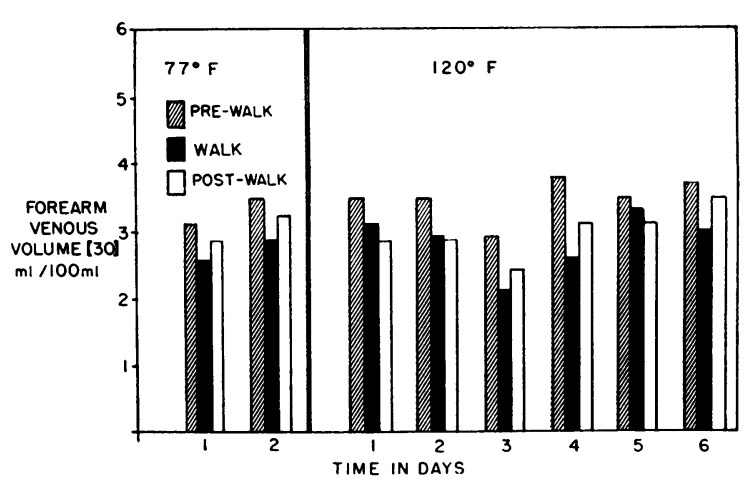

Fig. 2. Forearm venous volume [30] values for SEVEN MEN WHO WERE ACCLIMATIZED TO HEAT ON EIGHT ocASIONS. The averaged data that were obtained before, during and after walking on the treadmill in the control environment $\left(77^{\circ} \mathrm{F}\right)$ and in the hot environment $\left(120^{\circ}\right.$ F) are shown. 
with a Statham strain gauge and was recorded witl a Sanborn direct writing oscillograph. The subject was upright during these measurements. The reference point for the pressure was kept constant relative to the level of the treadmill and was at about the level of the subject's fifth intercostal space anteriorly.

On other and separate days venous pressures were measured with the subject recumbent immediately before and after walking. Pressures measured in the recumbent position were referred to a point $10 \mathrm{~cm}$ anterior to the back.

Probability and standard error were calculated from the original data rather than from the average values given in Tables $\mathrm{I}$ and II.

\section{RESULTS}

General observations. With one minor exception, the men completed all of the exercise periods in the hot environment. One subject was unable to complete the 30 minute period of walking on the first day of the second study. $\mathrm{He}$ walked for 23 minutes before becoming too weak to continue. Measurements were obtained just prior to the conclusion of the walking in this instance. All of the subjects reported dizziness, palpitation, weakness or nausea during the first two days of walking in the heat. In the days that followed they became acclimatized to heat to the extent that they no longer suffered these symptoms and completed the period of walking with relative ease.

Responses of the peripheral veins. Venous volume [30] during exercise in both environments was significantly lower $(p<0.01)$ than was the corresponding reading obtained just prior to the beginning of exercise (Figure 2). The change of venous volume [30] began within 3 to $5 \mathrm{~min}$ utes after the initiation of exercise and reached its greatest intensity within 10 minutes. This venous volume [30] then persisted with some random variation for the remaining 20 minutes of walking.

The greatest change of venous volume [30] during exercise occurred on the third and fourth days in the hot environment. These values were significantly $(p<0.01)$ lower than those observed during exercise in all days in the control environment and on all other days in the hot environment. On the other hand, there were no significant differences for venous volume [30] during exercise among all other days measured, i.e., all control days, and Days 1, 2, 5 and 6 in the

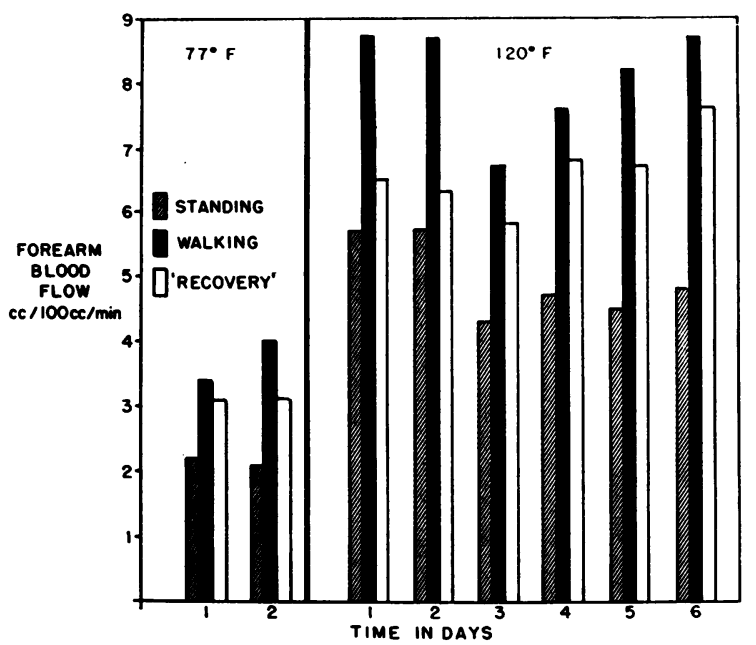

Fig. 3. Forearm BLOOD flow VAlues for EIGHT MEN WHO WERE ACCLIMATIZED TO HEAT ON EIGHT OCCASIONS. The averaged data that were obtained before, during and after walking on the treadmill in the control environment $\left(77^{\circ} \mathrm{F}\right)$ and in the hot environment $\left(120^{\circ} \mathrm{F}\right)$ are shown.

heat, as well as Days 7, 8 and 9 in the first series of heat exposures (Figure 2, Table I).

Blood flow and arterial blood pressure. The blood flow of the forearm just prior to walking was higher in the hot environment than in the control environment. Walking resulted in an increase in blood flow of the forearm in both environments. The increase of flow with walking in the hot environment was greater than that observed in the control environment (Figure 3). Blood flows during exercise were significantly lower $(p<0.01)$ on the third and fourth days in the heat than on the first and second, fifth and sixth, or (for the four subjects who participated) Days 7,8 and 9 in the hot environment (Table II).

The systolic and diastolic blood pressure of all of the subjects tended to be higher during walking in the hot environment than during walking in the control environment. Pulse pressure was highest during exercise on the third and fourth days in the hot environment (Table III).

$P$ ulse rate and rectal temperature. The mean pulse rates and rectal temperatures during exercise decreased as the heat phase progressed (Table III). The major portion of the total decrease in the pulse and rectal temperature had occurred by the fourth day in the hot environment. 
TABLE I

Average venous volume [30] for each subject on each day before walking, during walking and after walking in the control $\left(77^{\circ} \mathrm{F}\right)$ and hot $\left(120^{\circ} \mathrm{F}\right)$ environments

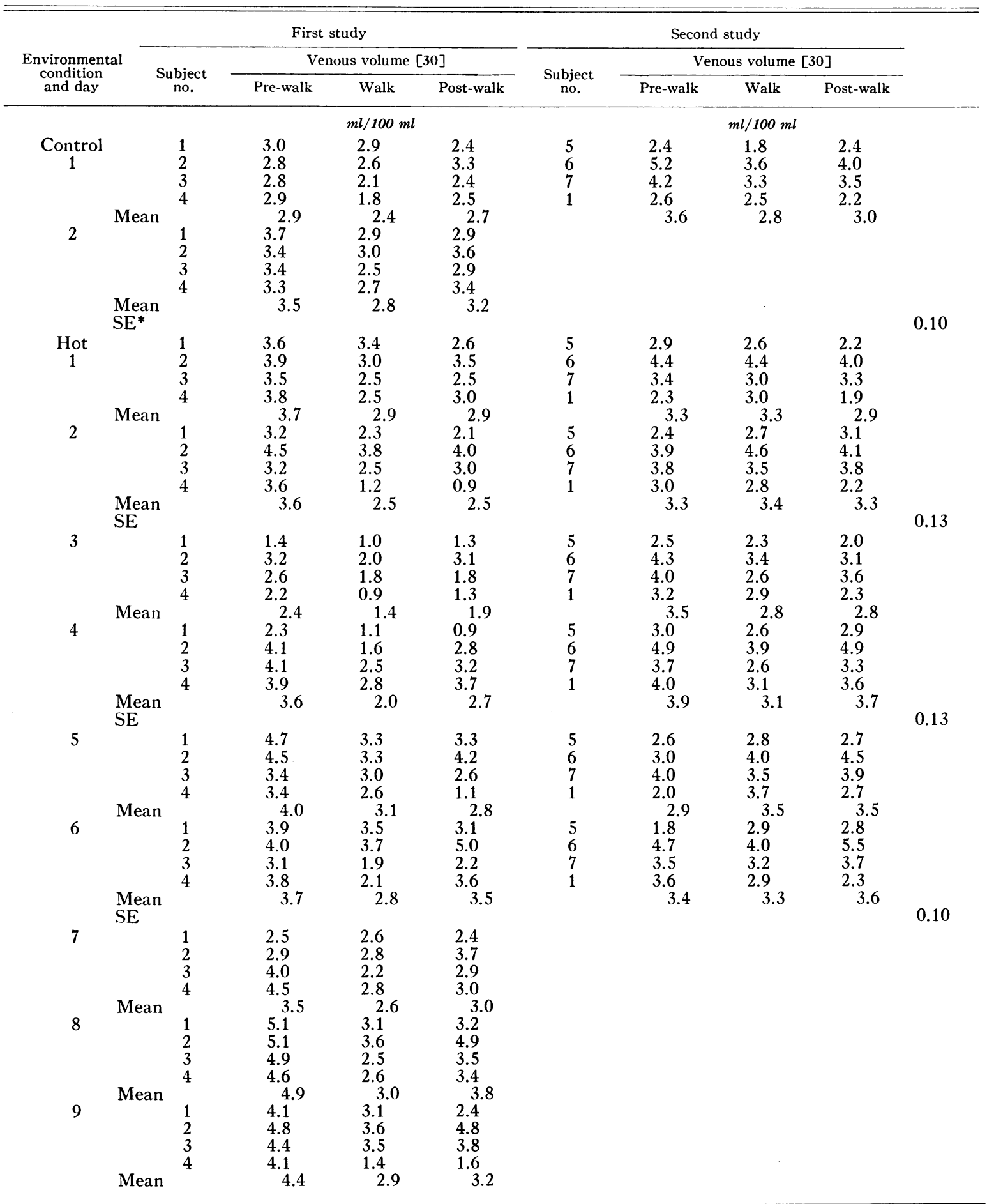

* Standard error calculated from the data obtained in both studies, during walking, on the preceding two days. 
TABLE II

Average blood flow for each subject on each day before walking, during walking and after walking in the control $\left(77^{\circ} \mathrm{F}\right)$ and hot $\left(120^{\circ} \mathrm{F}\right)$ environments

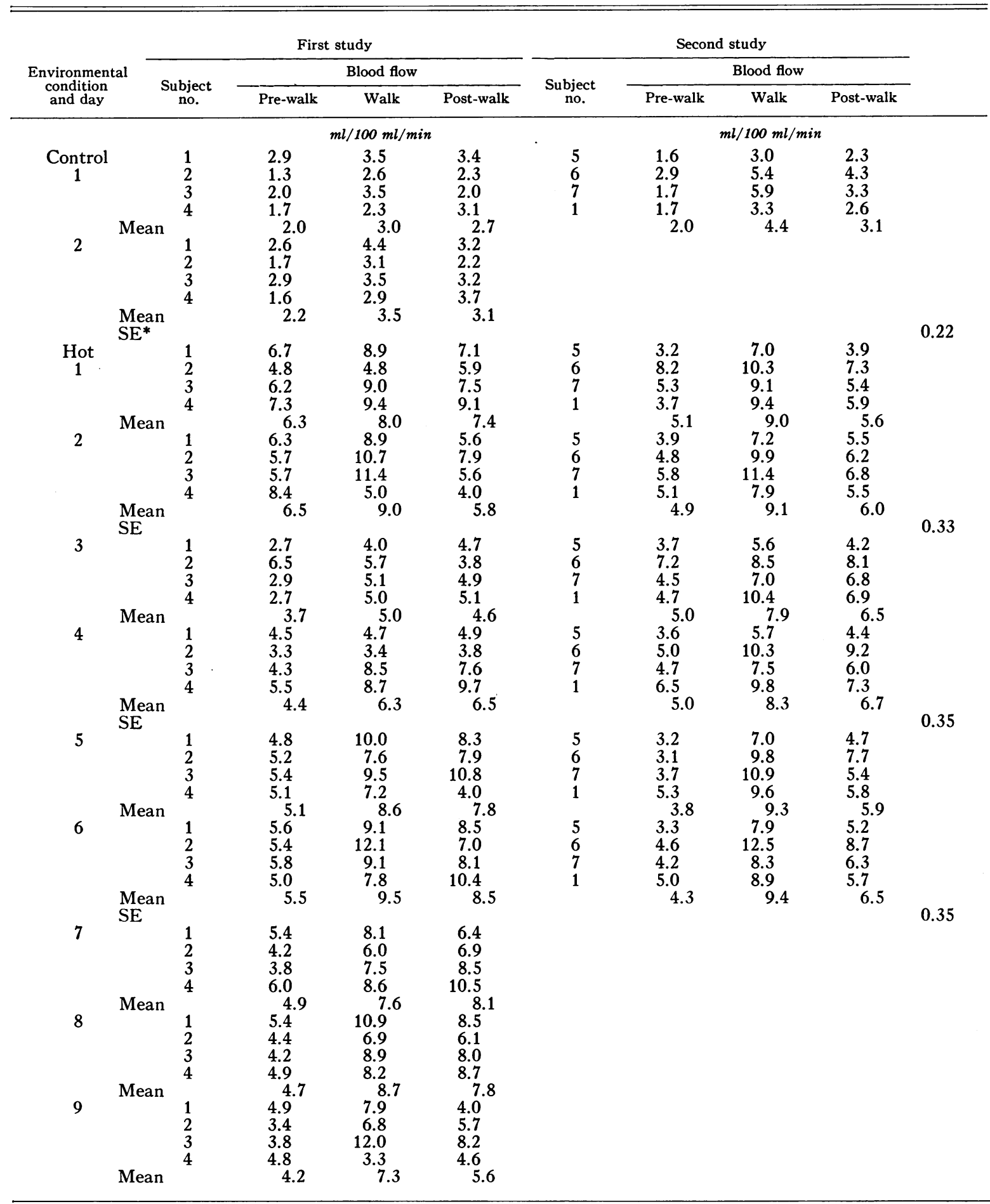

* Standard error calculated from the data obtained in both studies, during walking, on the preceding two days. 
TABLE III

- Rectal temperature (T.), pulse rate (P.), and arterial blood pressure (B.P.) just prior to the conclusion of the period of walking in the control $\left(77^{\circ} \mathrm{F}\right)$ and hot $\left(120^{\circ} \mathrm{F}\right)$ environments

\begin{tabular}{|c|c|c|c|c|c|c|c|c|}
\hline \multirow{2}{*}{$\begin{array}{l}\text { Environmental } \\
\text { condition } \\
\text { and day }\end{array}$} & \multicolumn{4}{|c|}{ First study } & \multicolumn{4}{|c|}{ Second study } \\
\hline & $\begin{array}{c}\text { Subject } \\
\text { no. }\end{array}$ & T. & P. & B.P. & $\begin{array}{c}\text { Subject } \\
\text { no. }\end{array}$ & $\mathrm{T}$. & P. & B.P. \\
\hline & & ${ }^{\circ} F$ & beats/min & $m m \mathrm{Hg}$ & & ${ }^{\circ} \mathrm{F}$ & beats/min & $m m \mathrm{Hg}$ \\
\hline $\begin{array}{c}\text { Control } \\
1\end{array}$ & $\begin{array}{r}1 \\
2 \\
3 \\
4 \\
\text { an }\end{array}$ & & $\begin{array}{l}124 \\
144 \\
128 \\
128 \\
\quad 131\end{array}$ & . & $\begin{array}{l}5 \\
6 \\
7 \\
1\end{array}$ & $\begin{array}{r}100.2 \\
99.8 \\
100.2 \\
100.4 \\
100.2\end{array}$ & $\begin{array}{l}152 \\
128 \\
136 \\
132 \\
137\end{array}$ & $\begin{array}{c}130 / 60 \\
150 / 70 \\
126 / 50 \\
140 / 60 \\
136 / 60\end{array}$ \\
\hline 2 & $\begin{array}{r}1 \\
2 \\
3 \\
4 \\
\text { an }\end{array}$ & & $\begin{array}{c}128 \\
128 \\
128 \\
136 \\
130\end{array}$ & $\begin{array}{c}130 / 80 \\
128 / 64 \\
130 / 60 \\
120 / 64 \\
127 / 67\end{array}$ & & & & \\
\hline $\begin{array}{c}\text { Hot } \\
1\end{array}$ & $\begin{array}{r}1 \\
2 \\
3 \\
4 \\
\text { an }\end{array}$ & $\begin{array}{r}101.3 \\
101.6 \\
100.6 \\
101.5 \\
101.0\end{array}$ & $\begin{array}{l}160 \\
184 \\
172 \\
180 \\
174\end{array}$ & $\begin{array}{l}130 / 60 \\
144 / 60 \\
138 / 60 \\
138 / 64 \\
138 / 61\end{array}$ & $\begin{array}{l}5 \\
6 \\
7 \\
1\end{array}$ & $\begin{array}{r}101.0 \\
100.2 \\
100.7 \\
101.5 \\
100.8\end{array}$ & $\begin{array}{c}180 \\
164 \\
176 \\
184 \\
176\end{array}$ & $\begin{array}{c}135 / 60 \\
130 / 50 \\
130 / 40 \\
148 / 50 \\
136 / 50\end{array}$ \\
\hline 2 & $\begin{array}{r}1 \\
2 \\
3 \\
4 \\
\text { an }\end{array}$ & $\begin{array}{c}101.2 \\
100.6 \\
100.6 \\
101.2 \\
101.0\end{array}$ & $\begin{array}{c}164 \\
172 \\
168 \\
172 \\
169\end{array}$ & $\begin{array}{l}160 / 50 \\
130 / 50 \\
170 / 50 \\
130 / 60 \\
148 / 52\end{array}$ & $\begin{array}{l}5 \\
6 \\
7 \\
1\end{array}$ & $\begin{array}{r}101.1 \\
99.6 \\
101.6 \\
101.6 \\
101.0\end{array}$ & $\begin{array}{c}188 \\
160 \\
168 \\
164 \\
170\end{array}$ & $\begin{array}{c}144 / 60 \\
140 / 45 \\
138 / 70 \\
153 / 50 \\
144 / 56\end{array}$ \\
\hline 3 & $\begin{array}{r}1 \\
2 \\
3 \\
4 \\
\text { an }\end{array}$ & $\begin{array}{c}100.5 \\
101.0 \\
99.5 \\
101.4 \\
100.6\end{array}$ & $\begin{array}{l}168 \\
176 \\
148 \\
164 \\
164\end{array}$ & $\begin{array}{l}156 / 50 \\
138 / 55 \\
194 / 70 \\
138 / 70 \\
156 / 61\end{array}$ & $\begin{array}{l}5 \\
6 \\
7 \\
1\end{array}$ & $\begin{array}{c}100.4 \\
99.6 \\
100.2 \\
101.2 \\
100.4\end{array}$ & $\begin{array}{l}188 \\
156 \\
164 \\
172 \\
170\end{array}$ & $\begin{array}{l}154 / 60 \\
152 / 60 \\
140 / 50 \\
146 / 50 \\
148 / 55\end{array}$ \\
\hline 4 & $\begin{array}{r}1 \\
2 \\
3 \\
4 \\
\text { an }\end{array}$ & & $\begin{array}{l}144 \\
148 \\
156 \\
156 \\
151\end{array}$ & $\begin{array}{c}140 / 56 \\
115 / 50 \\
120 / 40 \\
185 / 60 \\
140 / 54\end{array}$ & $\begin{array}{l}5 \\
6 \\
7 \\
1\end{array}$ & $\begin{array}{c}100.3 \\
99.3 \\
100.5 \\
100.8 \\
100.2\end{array}$ & $\begin{array}{l}168 \\
148 \\
160 \\
164 \\
160\end{array}$ & $\begin{array}{l}140 / 70 \\
130 / 60 \\
144 / 50 \\
146 / 50 \\
140 / 58\end{array}$ \\
\hline 5 & $\begin{array}{r}1 \\
2 \\
3 \\
4 \\
\text { an }\end{array}$ & $\begin{array}{r}100.6 \\
99.6 \\
100.2\end{array}$ & $\begin{array}{c}144 \\
140 \\
156 \\
152 \\
148\end{array}$ & $\begin{array}{l}146 / 54 \\
132 / 45 \\
158 / 60 \\
130 / 40 \\
142 / 50\end{array}$ & $\begin{array}{l}5 \\
6 \\
7 \\
1\end{array}$ & $\begin{array}{c}99.6 \\
99.8 \\
100.4 \\
100.5 \\
100.1\end{array}$ & $\begin{array}{l}168 \\
160 \\
160 \\
156 \\
161\end{array}$ & $\begin{array}{c}130 / 50 \\
144 / 60 \\
128 / 40 \\
136 / 50 \\
134 / 50\end{array}$ \\
\hline 6 & $\begin{array}{r}1 \\
2 \\
3 \\
4 \\
\text { an }\end{array}$ & $\begin{array}{c}100.4 \\
100.4 \\
100.0 \\
100.8 \\
100.4\end{array}$ & $\begin{array}{l}136 \\
156\end{array}$ & $\begin{array}{l}145 / 50 \\
130 / 50 \\
130 / 50\end{array}$ & $\begin{array}{l}5 \\
6 \\
7 \\
1\end{array}$ & $\begin{array}{r}100.6 \\
99.6 \\
100.2 \\
100.8 \\
100.3\end{array}$ & $\begin{array}{l}168 \\
140 \\
164 \\
164 \\
159\end{array}$ & $\begin{array}{c}120 / 60 \\
130 / 68 \\
138 / 50 \\
150 / 60 \\
134 / 60\end{array}$ \\
\hline 7 & $\begin{array}{r}1 \\
2 \\
3 \\
4 \\
\text { an }\end{array}$ & $\begin{array}{c}100.1 \\
99.6 \\
100.5 \\
100.7 \\
100.2\end{array}$ & $\begin{array}{l}152 \\
140\end{array}$ & $\begin{array}{l}136 / 50 \\
120 / 45 \\
164 / 60 \\
120 / 50 \\
135 / 51\end{array}$ & & & & \\
\hline 8 & $\begin{array}{r}1 \\
2 \\
3 \\
4\end{array}$ & $\begin{array}{r}100.2 \\
99.6 \\
100.3\end{array}$ & $\begin{array}{l}144 \\
144 \\
136\end{array}$ & $\begin{array}{l}154 / 54 \\
122 / 50 \\
150 / 60 \\
110 / 60 \\
134 / 56\end{array}$ & & & & \\
\hline 9 & $\begin{array}{r}1 \\
2 \\
3 \\
4 \\
\text { an }\end{array}$ & $\begin{array}{c}100.4 \\
99.6 \\
99.8 \\
100.2 \\
100.0\end{array}$ & $\begin{array}{l}144 \\
144\end{array}$ & $\begin{array}{l}142 / 60 \\
110 / 50 \\
120 / 40 \\
155 / 55 \\
132 / 51\end{array}$ & & & & \\
\hline
\end{tabular}


Venous pressure. The mean venous pressures obtained on two days in the control environment on the four subjects were: 12 (range 8 to 20) $\mathrm{mm} \mathrm{Hg}$ before walking; 10 (range 6 to 17 ) $\mathrm{mm}$ $\mathrm{Hg}$ during walking, and 11 (range 9 to 15 ) $\mathrm{mm}$ $\mathrm{Hg}$ after walking. The average venous pressures measured in this way on the second day in the hot environment were 13 (range 12 to 16 ), 9 (range 8 to 12 ) and 13 (range 10 to 15 ) $\mathrm{mm} \mathrm{Hg}$, respectively. These pressures on the fourth day in the hot environment were 11 (range 10 to 12 ), 9 (range 8 to 10 ) and 11 (range 8 to 14 ) $\mathrm{mm} \mathrm{Hg}$, respectively.

All venous pressures obtained with the subject recumbent before and after walking on one day in the control environment and on the third day in the hot environment were below $12 \mathrm{~mm} \mathrm{Hg}$.

\section{DISCUSSION}

Acclimatization to a hot environment by intermittent work is a well defined process that is easily observed in man (9). It is possible to induce this state by repeated performance of a task at high environmental temperatures even if the subject lives in a cool environment the rest of the time (2). As the subject becomes acclimatized to heat the symptoms of heat exhaustion during work diminish. His ability to perform the standard task improves. Weakness of the exercising extremities, and dizziness or syncope no longer occur. These subjective evidences of acclimatization to heat were virtually complete by the third day of the studies described herein. The diminishing increment of the pulse rate with exercise in the heat continued after the third day in these studies however.

The responses of the forearm veins and arterioles observed in this study were among the early evidence of acclimatization to heat. In addition, they coincided with the early subjective improvements. It seems reasonable, therefore, to infer that the peripheral vasomotor responses were importantly associated with the acclimatization process. On the other hand, the disappearance of these vasomotor adaptations on later heat days in the face of continued acclimatization encourages a search for other mechanisms that maintain the circulation during later days in the heat.

Previous studies have shown that decreases in venous volume [30] are indicative of venoconstriction (6). Infusions of epinephrine or norepinephrine did not alter the volume of the forearm when the transmural pressure of the local veins was $1 \mathrm{~mm} \mathrm{Hg}$ as a result of the external pressure of the water in the plethysmograph. Since most of the blood of the forearm is in the veins $(10,11)$ it can be assumed that these venoconstricting stimuli (12) did not change the volume of the veins before the pressure-volume curves were obtained. The venous pressure-volume curves recorded during the venoconstrictor stimulus were lower than those obtained before the stimulus was applied (6). The vasodilating stimulus of a marked increase in environmental temperature did not alter the venous pressure-volume curve (6). Thus, the starting point of a venous pressure-volume curve is one of a small, constant venous volume and the smaller the volume of blood that these veins will accept at a transmural pressure of $30 \mathrm{~mm} \mathrm{Hg}$ the greater the degree of venoconstriction. Further, if venous pressure is unchanged and the venous pressure-volume curve is lowered by some stimulus, then it may be concluded that the naturally occurring volume of the veins of the forearm is lower (6). When the blood volume is unchanged, as was true of the basal blood volume in experiments similar to those of the present study (8), the further conclusion that blood has shifted from the veins of the forearm to some other area is reasonable. The results of the present experiments indicate that. exercise resulted in constriction of the veins with movement of blood out of the forearm. This response was more intense on the third and fourth days of acclimatization to heat than on other days in the hot environment. The failure to find marked changes in peripheral venous pressure does not necessarily indicate that there were no changes in the effective pressure of the blood in the right atrium (7). The movement of blood out of the forearm with exercise may have contributed to maintaining the filling pressure of the right ventricle especially on the third and fourth days in the hot environment, as is suggested by Bass and Henschel (13).

Acclimatization to a hot environment is also characterized by a gradual improvement in the ability of the body to rid itself of the heat produced by exercise. Two important factors that deter- 
mine the rate of heat loss in an environment whose temperature exceeds that of the body are the rate of peripheral blood flow, particularly to the skin, and the rate of evaporation from the skin. If the blood flow in the forearm is even a partial reflection of the state of the arterioles near the surface of the body then the high blood flows during the first, second, fifth, sixth and subsequent days in the hot environment favored the loss of heat. Blood flow of the forearm is primarily that of muscle while heat dissipation is more dependent upon the flow of blood in the skin. Thus, the importance of the observations of blood flow in the forearm relative to the rate of heat dissipation is limited. The rate of evaporation with exercise is high in a hot environment and has been found to become even higher after several days (14).

The relationship between peripheral venomotor responses and the dissipation of heat remains to be evaluated. There is some evidence that the major proportion of heat that is lost from the blood occurs when the blood is flowing through the subpapillary venous system of the skin (15). If this be true, then the rate at which a unit volume of blood passes through the peripheral veins might affect the amount of heat lost to the environment. This would mean that the greater the velocity of the flow of blood through the peripheral veins the smaller the amount of heat that would be lost per unit volume of blood so long as the circumstances were such that the temperature of the blood did not come into complete equilibrium with the temperature at the surface of the body, regardless of the velocity of the flow of blood in the veins. Although the importance of this consideration remains obscure it can be pointed out that the effects of the peripheral venomotor responses with respect to the loss of heat would parallel the effects of the peripheral arteriolar responses since their relative states of dilatation were much the same from day to day during walking in the hot environment.

\section{SUMMARY AND CONCLUSIONS}

1. Seven normal young men were acclimatized to heat on eight occasions by walking on a treadmill for 30 minutes four times a day at an environmental temperature of $120^{\circ} \mathrm{F}$ dry bulb and $80^{\circ} \mathrm{F}$ wet bulb. Four subjects were acclimatized to heat in this manner for nine days in the summer and four subjects were acclimatized to heat in an identical study for six days in the fall.

2. The responses to exercise of the veins and arterioles of the forearm during acclimatization to the heat were measured by plethysmographic techniques.

3. The forearm veins constricted with walking in a control environment $\left(77^{\circ} \mathrm{F}\right)$ as well as with walking in the hot environment. The degree of venoconstriction with walking was greatest on the third and fourth days of exposure to the hot environment.

4. The forearm arterioles dilated during walking at normal environmental temperatures. This dilatation with walking was greater in the hot environment. The degree of dilatation was less on the third and fourth days during walking in the hot environment than on the first and second or on the final days in this environment.

5. The disappearance of the symptoms of heat exhaustion with exercise (dizziness, weakness and nausea) coincided with the onset of maximal venoconstriction and minimal arteriolar dilatation on the third day of the acclimatization process. The maximal venoconstriction and minimal arteriolar dilatation with walking did not persist after the fourth day in the hot environment. Subjective and objective evidences of acclimatization to heat were nevertheless well maintained for the remainder of each of the studies.

6 . The results of these studies support the concept that important adaptations in acclimatization of man to exercise in a hot environment take place in the cardiovascular system. The peripheral vascular adaptations as observed in the forearm blood vessels appear to be an important aspect of the cardiovascular responses to exercise in the heat.

\section{REFERENCES}

1. Darling, C. D. Diseases due to physical agents in A Textbook of Medicine, R. L. Cecil and R. F. Loeb, Eds. Philadelphia, W. B. Saunders, 1959, p. 476.

2. Bean, W. B., and Eichna, L. W. Performance in relation to environmental temperature. Reactions of normal young men to desert environment. Fed. Proc. 1943, 2, 144.

3. Taylor, H. L., Henschel, A. F., and Keys, A. Cardiovascular adjustments of man in rest and 
work during exposure to dry heat. Amer. J. Physiol. 1943, 139, 583.

4. Dill, D. B. Life, Heat and Altitude; Physiological Effects of Hot Climates and Great Heights. Cambridge, Harvard Univ. Press, 1938.

5. Whitney, R. J. Circulatory changes in the forearm and hand of man with repeated exposure to heat. J. Physiol. 1954, 125, 1.

6. Wood, J. E., and Eckstein, J. W. A tandem forearm plethysmograph for study of acute responses of the peripheral veins of man: The effect of environmental and local temperature change and the effect of pooling blood in the extremities. J. clin. Invest. 1958, 37, 41.

7. Eckstein, J. W., and Hamilton, W. K. Changes in transmural central venous pressure in man during hyperventilation. J. clin. Invest. 1958, 37, 1537.

8. Bass, D. E., Buskirk, E. R., Iampietro, P. F., and Mager, M. Comparison of blood volume during physical conditioning, heat acclimatization and sedentary living. J. appl. Physiol. 1958, 12, 186.

9. Bass, D. E., Kleeman, C. R., Quinn, M., Henschel, A., and Hegnauer, A. H. Mechanisms of acclima- tization to heat in man. Medicine (Baltimore) 1955, 34, 323.

10. Landis, E. M., and Hortenstine, J. C. Functional significance of venous blood pressure. Physiol. Rev. 1950, 30, 1.

11. Litter, J., and Wood, J. E. The volume and distribution of blood in the human leg measured in vivo. I. The effects of graded external pressure. J. clin. Invest. 1954, 33, 798.

12. Burch, G. E., and Murtadha, M. A study of the venomotor tone in a short intact venous segment of the forearm of man. Amer. Heart J. 1956, 51, 807.

13. Bass, D. E., and Henschel, A. Responses of body fluid compartments to heat and cold. Physiol. Rev. 1956, 36, 128.

14. Eichna, L. W., Park, C. R., Nelson, N., Horvath, S. M., and Palmes, E. D. Thermal regulation during acclimatization in a hot, dry (desert type) environment. Amer. J. Physiol. 1950, 163, 585.

15. Cooper, T., Randall, W. C., and Hertzman, A. B. Vascular convection of heat from active muscle to overlying skin. J. appl. Physiol. 1959, 14, 207. 